Saudi Journal of Oral and Dental Research

Abbreviated Key Title: Saudi J Oral Dent Res

ISSN 2518-1300 (Print) |ISSN 2518-1297 (Online)

Scholars Middle East Publishers, Dubai, United Arab Emirates

Journal homepage: https://saudijournals.com/sjodr

\title{
Knowledge and Awareness of Prosthetic Restoration of Endodontically Treated Teeth among the Dental Doctors of Jazan, Saudi Arabia
}

Dr. Buthina Hamza Alaki ${ }^{*}$ Dr. Othman Ibrahim Aqeeli, Dr. Omar Sulaiman Laghabi, Dr. Fatima Sultana

College of Dentistry, Jazan University, Jazan, Saudi Arabia

DOI: $10.36348 /$ sjodr.2021.v06i01.007

| Received: 23.12.2020 | Accepted: 11.01.2021 | Published: 14.01.2021

*Corresponding author: Dr. Buthina Hamza Alaki

\section{Abstract}

Introduction: After the elimination of endodontic infection the teeth becomes fragile, brittle and can easily fracture when compared to the natural teeth. The removed teeth and the dental pulp need to be replaced after the endodontic therapy to prevent inconvenience to the patient in chewing, biting and speaking. Aim: The main aim of this study is to assess the knowledge and awareness of dental doctors of Jazan about the prosthetic restorations of endodontically treated teeth. Methodology: A pre-designed questionnaire was circulated online using Google form to measure the knowledge and awareness of the dental doctors about the prosthetic restorations of the endodontically treated teeth. The results of the survey of elucidating the awareness of dental doctors in Jazan was recorded. The result of this survey was analysed using the SPSS software. Results: The above data analysis of this survey to evaluate and access the knowledge and awareness of the dental doctors of Jazan, in Saudi Arabia showed good results. Most of the dental doctors participating in this survey from Jazan are highly experienced and have excellent comprehension about the prosthetic restorations after the endodontic treatment.

Keywords: Prosthetic restoration, endodontically treated teeth, endodontics, Jazan.

Copyright () 2021 The Author(s): This is an open-access article distributed under the terms of the Creative Commons Attribution 4.0 International License (CC BY-NC 4.0) which permits unrestricted use, distribution, and reproduction in any medium for non-commercial use provided the original author and source are credited.

\section{INTRODUCTION}

Endodontics deals with the treatment of the diseases related to the Dental pulp by Root canal treatment, Periradicular surgery, apicoectomy, pulpcapping, pulpal regeneration, pulpotomy, hemisection and apexification. The dental pulp includes fibrous tissue, nerves, lymphatic tissue, arterioles and venules. Endodontics involves the treatment and removal of the diseased, infected and inflammed pulp tissue.

The removed teeth and the dental pulp need to be replaced after the endodontic therapy to prevent inconvenience to the patient in chewing, biting and speaking. Hence they are replaced by fixed or removable prostheses. The successful treatment of the tooth infected by micro organisms not only depends on an excellent endodontic treatment but also on an excellent reconstruction of the tooth. The prosthetic restoration is done on the tooth that is treated by Endodontic therapy [1].

After the elimination of endodontic infection the teeth becomes fragile, brittle and can easily fracture when compared to the natural teeth. Usually an intraradicular post is placed inside the root canal after the endodontic therapy. Several studies suggest that the post space preparation and posts cementation can make the root canal weak leading to fracture of the root [2]. The ideal material used for the posts should possess the physical characteristics same as Dentin along with the modulus of elasticity, coefficient of thermal expansion and comprehensive strength [3].

The tooth structure can be attained by using the adhesive restorations that creates minimal invasive preparations [4]. In recent times the ultra high molecular weight polyethylene (UHMWPE) fiber reinforcement systems are getting much popularity. UHMWPE has many clinical applications [5]. Due to the special property of UHMWPE, that it adapts to the root canal wall without requiring additional enlargement of the root canal after the endodontic therapy has increased its clinical value [6].

The endodontically treated teeth can be restored by the prosthetic treatment. Most of the prosthetic therapies after the Endodontic treatment may involve the use of direct restorations like amalgam, cements and resin composites or crowns [7]. The infected root canal can be sealed by using calcium 
Buthina Hamza Alaki et al; Saudi J Oral Dent Res, Jan 2021; 6(1): 39-43

hydroxide dressing that was invented in the year 1991 which evidently eliminates the bacteria in the infected root canals [8]. Calcium hydroxide is simple to prepare, resorbable, readily available and is more soluble in glycerine when compared to water [9]. There exists a direct relation between the structure of the tooth remaining after the Endodontic treatment and the fracture resistance [10].

The ideal post for the root canal after the Endodontic treatment should help to preserve the tooth structure, maintain resistance and retention, ferrule effect, retrievability and failure mode [11].

\section{AIM AND OBJECTIVES}

The main aim of this study is to assess the knowledge and awareness of dental doctors of Jazan about the prosthetic restorations of endodontically treated teeth. This can be attained by:

\section{SPECIFIC OBJECTIVES}

- Carrying out a survey to evaluate the awareness of the dental doctors practising in Jazan, Saudi Arabia about the various prosthetic restorations of endodontically treated teeth.

- Determining the attitude of the dental doctors regarding the need for restoration of the endodontically treated teeth.

\section{METHODOLOGY}

A pre-designed questionnaire was circulated online using Google form to measure the knowledge and awareness of the dental doctors about the prosthetic restorations of the endodontically treated teeth. The results of the survey of elucidating the awareness of dental doctors in Jazan was recorded. This study was carried out in the year 2020. The questionnaire was designed in English language and later is translated into Arabic language. The Questionnaire in both English and Arabic was circulated online to the dental doctors of Jazan, in Saudi Arabia. The questionnaire includes the questions related to the demographic data of the dental doctors followed by questions related to knowledge and Awareness about prosthetic restorations of endodontically treated teeth.

\section{DATA COLLECTION}

The results of this cross-sectional study of determining the knowledge and awareness of dental doctors of Jazan, in Saudi Arabia was recorded. The result of this survey was analysed using the SPSS software. The frequencies and percentage of the results of elucidating the awareness of dental doctors was done using the $\mathrm{P}$ value less than or equal to 0.05 .

\section{Data Management and Analysis Plan}

The data collected from the online survey was analysed using the computer software Statistical package for social sciences that is SPSS 16. The frequencies and percentages of the responses from the dental doctors of Jazan in Saudi Arabia is done and the descriptive statistics is attained and the mean, standard deviation and frequency distribution is calculated. Data inscription was done in a password-protected computer in a database created by the Principal Investigator working on this project. A hard copy of the data and Identification variable is maintained in a locked file cabinet in the research coordinator office. Only those involved in the study have access to data. The data is accessible only to the persons involved in the study. All data is identified. Data is restrained vaguely.

\section{RESULTS}

About 93 dental doctors of Jazan in Saudi Arabia answered the survey related to the prosthetic restorations of endodontically treated teeth. 1(1.1\%) participant belong to age group 19-20 years, 19(20.4\%) are in 21-25 years age group, $31(33.3 \%)$ are in $26-30$ years age group and $42(45.2 \%)$ belonged to age group $>30$ years. Majority of the participants are males $67(72.1 \%)$ and remaining $26(27.9 \%)$ are females.

About $28(30.1 \%)$ of the dental doctors participating in the study has 1 year of experience, while $14(15.1 \%)$ of them has 2 years of experience, 7 $(7.5 \%)$ of the participants has 3 years of experience, 4 $(4.5 \%)$ of them has 4 years of experience, $3(3.2 \%)$ of the participants has 5 years of experience, $10(10.7 \%)$ of the participants has 5-10 years of experience and 27 $(29.1 \%)$ of the participants of this survey has more than 10 years of experience.

$36(38.7 \%)$ of the participants are working in the private sector, $42(45.1 \%)$ are working in the public sector and $15(16.1 \%)$ are unemployed. Majority of the dental doctors from Jazan participating in the survey are Saudi nationals whereas $8(8.6 \%)$ of them are nonSaudi nationals.

\begin{tabular}{|l|l|l|}
\hline DEMOGRAPHIC CHARACTERS & FREQUENCY & PERCENTAGE \\
\hline Age & & \\
$19-20$ years & 1 & 1.1 \\
21 - 25 years & 19 & 20.4 \\
26 - 30 years & 31 & 33.3 \\
$>30$ years & 42 & 45.2 \\
\hline Gender & & \\
Female & 26 & 27.9 \\
Male & 67 & 72.1 \\
\hline
\end{tabular}


Buthina Hamza Alaki et al; Saudi J Oral Dent Res, Jan 2021; 6(1): 39-43

\begin{tabular}{|l|l|l|}
\hline Experience & & \\
1 year & 28 & 30.1 \\
2 year & 14 & 15.1 \\
3 year & 7 & 7.5 \\
4 year & 4 & 4.3 \\
5 year & 3 & 3.2 \\
5-10 year & 10 & 10.7 \\
More than 10 year & 27 & 29.1 \\
\hline Working & & \\
In Private sector & 36 & 38.7 \\
In Public sector & 42 & 45.1 \\
Is Unemployed & 15 & 16.1 \\
\hline Nationality & & \\
Saudi & 85 & 91.4 \\
Non-Saudi & 8 & 8.6 \\
\hline
\end{tabular}

According to statistics of this survey, most of the dental doctors that participated in this crosssectional study are well aware about the prosthetic restorations after the endodontic therapy. About 84 $(90.3 \%)$ are aware about prosthetic rehabilitation can restore the lost teeth after the endodontic therapy in Saudi Arabia. 86 (92.4\%) are aware that Endodontically treated teeth dry out over time with their dentin undergoes changes in collagen cross-linking. 80 $(86.0 \%)$ are aware that endodontically treated teeth are more brittle than the non-endodontically treated teeth. $83(89.2 \%)$ are aware that the endodontically treated teeth are more susceptible to fracture when compared to non treated teeth.

Around $81(87.0 \%)$ are aware that the Loss of tooth structure due to caries and trauma also contributes to fracture of endodontically treated teeth. $84(90.3 \%)$ are aware about the crown restorations are failed due to loss of tooth structure. $91(97.9 \%)$ are aware that the use of post and core can strengthen the endodontically treated teeth. About $79(84.9 \%)$ of the dental doctors from Jazan that some studies suggests weakening the root structure with subsequent root fracture.

\begin{tabular}{|c|c|c|c|}
\hline $\begin{array}{l}\text { Awareness About Prosthetic Restoration Of Endodontically Treated } \\
\text { Teeth In Dental Services }\end{array}$ & YES (\%) & NO (\%) & $\begin{array}{l}\text { P- } \\
\text { Value }\end{array}$ \\
\hline $\begin{array}{l}\text { Are you aware about prosthetic rehabilitation can restore the lost teeth after the endodontic } \\
\text { therapy in Saudi Arabia? }\end{array}$ & $84(90.3 \%)$ & $9(9.7 \%)$ & 0.015 \\
\hline $\begin{array}{l}\text { Are you aware that Endodontically treated teeth dry out over time with their dentin } \\
\text { undergoes changes in collagen cross-linking? }\end{array}$ & $86(92.4 \%)$ & $7(7.6 \%)$ & 0.022 \\
\hline $\begin{array}{l}\text { Are you aware that endodontically treated teeth are more brittle than the non- } \\
\text { endodontically treated teeth? }\end{array}$ & $80(86.0 \%)$ & $13(14.0 \%)$ & 0.025 \\
\hline $\begin{array}{l}\text { Are you aware that the endodontically treated teeth are more susceptible to fracture when } \\
\text { compared to non treated teeth? }\end{array}$ & $83(89.2 \%)$ & $10(10.8 \%)$ & 0.020 \\
\hline $\begin{array}{l}\text { Are you aware that the Loss of tooth structure due to caries and trauma also contributes to } \\
\text { fracture of endodontically treated teeth? }\end{array}$ & $81(87.0 \%)$ & $12(13.0 \%)$ & 0.027 \\
\hline Are you aware that the crown restorations are failed due to loss of tooth structure? & $84(90.3 \%)$ & $9(9.7 \%)$ & 0.015 \\
\hline Are you aware that the use of post and core can strengthen the endodontically treated teeth? & $91(97.9 \%)$ & $2(2.1 \%)$ & 0.013 \\
\hline $\begin{array}{l}\text { Are you aware that some studies suggests weakening the root structure with subsequent } \\
\text { root fracture? }\end{array}$ & $79(84.9 \%)$ & $14(15.1 \%)$ & 0.009 \\
\hline $\begin{array}{l}\text { Are you aware that the primary function of post is to provide retention to core to support } \\
\text { the coronal restoration? }\end{array}$ & $82(88.2 \%)$ & $11(11.8 \%)$ & 0.029 \\
\hline Are you aware about the active and passive post? & $88(94.6 \%)$ & $5(5.4 \%)$ & 0.019 \\
\hline Are you aware about the parallel and tapered posts? & $90(96.7 \%)$ & $3(3.3 \%)$ & 0.020 \\
\hline Are you aware about the custom cast post and cores? & $92(98.9 \%)$ & $1(1.1 \%)$ & 0.016 \\
\hline Are you aware about the prefabricated posts and cores? & $89(95.6 \%)$ & $4(4.4 \%)$ & 0.019 \\
\hline Are you aware about the ceramic and zirconium posts? & $88(94.6 \%)$ & $5(5.4 \%)$ & 0.019 \\
\hline Are you aware about the fiber posts? & $84(90.3 \%)$ & $9(9.7 \%)$ & 0.015 \\
\hline $\begin{array}{l}\text { Are you aware that the shearing forces acting on anterior teeth are more frequently restored } \\
\text { with posts than posterior teeth? }\end{array}$ & $91(97.9 \%)$ & $2(2.1 \%)$ & 0.013 \\
\hline $\begin{array}{l}\text { Are you aware that the selection of post design and post system is important since it acts } \\
\text { major deciding factor longevity of tooth andlong-term success of endodontic treatment? }\end{array}$ & $87(93.5 \%)$ & $6(6.5 \%)$ & 0.023 \\
\hline
\end{tabular}

$82(88.2 \%)$ of the candidates participants are well aware of the primary function of post is to provide retention to core to support the coronal restoration. 88 (94.6\%) of them are aware about the active and passive post. $90(96.7 \%)$ are aware about the parallel and tapered posts. $92(98.9 \%)$ are aware about the custom cast post and cores. $89(95.6 \%)$ are aware about the prefabricated posts and cores. $88(94.6 \%)$ of the dental doctors $84(90.3 \%)$ are aware about the fiber post, 91 $(97.9 \%)$ are aware about the shearing forces acting on 
Buthina Hamza Alaki et al; Saudi J Oral Dent Res, Jan 2021; 6(1): 39-43

anterior teeth are more frequently restored with posts than posterior teeth. $87(93.5 \%)$ are aware that the selection of post design and post system is important since it acts major deciding factor longevity of tooth and long-term success of endodontic treatment.

The above data analysis of this survey to evaluate and access the knowledge and awareness of the dental doctors of Jazan, in Saudi Arabia showed good results. Most of the dental doctors participating in this survey from Jazan are highly experienced and have excellent comprehension about the prosthetic restorations after the endodontic treatment.

\section{DISCUSSION}

In review of the literature, in $17^{\text {th }}$ Century to assist the retention of the crown, Fauchard inserted the canal made with wooden dowels and the retention of the dowels was favoured by the nature of wood absorbing moisture [12]. In the year 1869, the porcelain faced crown with gold lined root canal was secured by a screw made of metal posts. Amidst the $18^{\text {th }}$ Century, a tube was developed by Clark that allowed drainage from the apical area of the canal [12]. Richmond in 1878 , for the first time introduced a threaded tube inside a canal with screw retained crown [12].

The Richmond Crown that was a single piece post retained crown made with porcelain facing to function as a bridge retainer was invented in the late 19 century. In the year 1958, Hampson EL and Demas NC replaced the threaded tube with a single piece dowel crown [12]. Sorensen J.A and J.T. Martinoff reported the high risk of un-restoreable cusp fracture in endodontically treated teeth with intra-coronal restorations [13]. They also reported that the use of crown can enhance the restoration success of endodontically treated posterior teeth. In 1987, Eissman and Radke explained the ferrule effect of casting a metal ring that protects the integrity of the endodontically treated tooth structure.

Fernandez AS in 2001, proposed the development of the hydrostatic pressure inside the root canal during the cementation process [14]. Vichi 2000 and Freedman 2001 emphasized the use of restoration in a colour close to that of natural teeth. In the $20^{\text {th }}$ Century, the fixed dental prosthesis were evolved exponentially.

In the modern technologies in dentistry, various fields and specialities have merged together to give patient good services, however the restoration of the endodontically treated teeth is still a challenge. A varied improvisation and enhancement in the posts have been done, but still it could fail sometimes in case of endodontically treated teeth. The failure rate is low, but still more research and development need to be done to make this negligible in the field of prosthetic restoration of endodontically treated teeth. Root fracture and posts loosening are the most encountered clinical complications of prosthetic restorations.

To follow the correct procedure of prosthetic restoration, a dental doctor must have good knowledge about it after the endodontic therapy. Thus in this study a brief introduction about the requirement of restoration in the endodontically treated teeth is explained and also the evaluation of the knowledge and awareness among the dental doctors of Jazan is done related to prosthetic restoration of endodontically treated teeth. The majority of the participants $(45.2 \%)$ were above 30 years of age. $72.1 \%$ of the dental doctors were males. $29.1 \%$ of the dental doctors in Jazan are highly qualified of more than 10 years experience. About $45.1 \%$ works in the private sector and $91.4 \%$ are Saudi Nationals that participated in this study.

The results of this survey are similar when compared to the results of the studies by Alenzi A et al., [15]. The intraradicular fiber posts are cheap and biocompatible and is used to bond to dentin and restore the endodontically treated teeth. A well designed randomized controlled clinical trials are unavailable in the scientific literature. The factors that effect the selection of posts may be: root length, tooth anatomy, post width, canal configuration and post adaptability, coronal structure, position of the tooth in the arch, stress, torsional force, role of hydrostatic pressure, post design, post material, material compatibility, bonding ability, core retention, retrievability and esthetics. The ideal prefabricated posts should be sufficient in length, parallel in shape, cemented, standardized to size of existing drills, vented, and have greater resistance to dislodgement.

In the year 1988, Kanca et al., reported that the use of intra coronal direct placement composite restorations gives high success rate in restoring the endodontically treated posterior teeth [12]. The endodontically treated teeth need to be determined for restoration by checking the apical seal, sensitivity to percussion and inflammation. Sorenson and Engelman reported that parallel sided posts causes less tooth fracture when compared with tapered posts [13]. In order to carry out the restoration of the endontically treated teeth, the endodontic treatment must be successful, The dental practitioner should reduce the loss of tooth structure in both endodontic and posts preparation; the apical seal need to be maintained adequately to reduce the length of posts; and the concentration of the posts during the post insertion need to be minimized.

\section{CONCLUSION}

Most of the dental doctors from Jazan that participated in this study, have good knowledge and awareness about the prosthetic restorations of endodontically treated teeth. The dental doctors are highly educated and most of them have good practising 
Buthina Hamza Alaki et al; Saudi J Oral Dent Res, Jan 2021; 6(1): 39-43

experience in the field. The doctors are well aware about the prosthetic restorations that can be done after the endodontic therapy. More research need to be done including all the dental care takers in different regions of Saudi Arabia to estimate more clear results.

\section{LIMITATIONS}

This study was carried out in only the dental doctors of Jazan, the same surveys can be done in other parts of Saudi Arabia.

\section{ACKNOWLEDGEMENT}

We would like to specially thank all the dental doctors from Jazan, Saudi Arabia who participated in this survey and also for their time and co-operation.

\section{ETHICAL CONSIDERATIONS}

\section{Compliance with Ethical Standards}

Ethical Approval: This proposal contain survey studies with human participants that is the dental doctors practising in Saudi Arabia performed by any of the authors.

Conflict of Interest: The authors do not have any commercial associations that might pose or create a conflict of interest with information presented in this communication. No intramural or extramural funding supported any aspect of this work.

\section{REFERENCES}

1. Sedgley, C. M., \& Messer, H. H. (1992). Are endodontically treated teeth more brittle?. Journal of endodontics, 18(7), 332-335.

2. Costa, L. C. S., Pegoraro, L. F., \& Bonfante, G. (1997). Influence of different metal restorations bonded with resin on fracture resistance of endodontically treated maxillary premolars. The Journal of prosthetic dentistry, 77(4), 365-369.

3. Seefeld, F., Wenz, H. J., Ludwig, K., \& Kern, M. (2007). Resistance to fracture and structural characteristics of different fiber reinforced post systems. Dental Materials, 23(3), 265-271.

4. Grandini, S., Goracci, C., Monticelli, F., Tay, F. R., $\&$ Ferrari, M. (2005). Fatigue resistance and structural characteristics of fiber posts: three-point bending test and SEM evaluation. Dental Materials, 21(2), 75-82.

5. Akkayan, B., \& Gülmez, T. (2002). Resistance to fracture of endodontically treated teeth restored with different post systems. The Journal of prosthetic dentistry, 87(4), 431-437.

6. Creugers, N. H. J., Mentink, A. G. B., \& Käyser, A. F. (1993). An analysis of durability data on post and core restorations. Journal of Dentistry, 21(5), 281284.

7. Richardson, J. (1880). A practical treatise on mechanical dentistry. Lindsay and Blakiston.148153.
8. Goodacre, C. J., \& Baba, N. Z. (2008). Restoration of endodontically treated teeth. In: Ingle, J. I., \& Bakland, L. K., eds. Endodontics, 6th edn. Toronto, Canada: BC Decker Inc.

9. Kishen, A. (2006). Mechanisms and risk factors for fracture predilection in endodontically treated teeth. Endodontic topics, 13(1), 57-83.

10. Goodacre, C. J., \& Spolnik, K. J. (1994). The prosthodontic management of endodontically treated teeth: a literature review. Part I. Success and failure data, treatment concepts. Journal of Prosthodontics, 3(4), 243-250.

11. Goldsmith, M., Gulabivala, K., \& Knowles, J. C. (2002). The effect of sodium hypochlorite irrigant concentration on tooth surface strain. Journal of Endodontics, 28(8), 575-579.

12. Al-Dhalaan, R. Prosthodontic management of endodontically treated teeth; factors determining post selection, foundation restorations and review of success failure data. Back to cited text, (2).

13. Sorensen, J. A., \& Martinoff, J. T. (1985). Endodontically treated teeth as abutments. Journal of Prosthetic Dentistry, 53(5), 631-636.

14. Fernandes, A. S., \& Dessai, G. S. (2001). Factors affecting the fracture resistance of post-core reconstructed teeth: a review. International Journal of Prosthodontics, 14(4):355-63.

15. Alenzi, A., Samran, A., Samran, A., Nassani, M. Z., Naseem, M., Khurshid, Z., \& Özcan, M. (2018). Restoration strategies of endodontically treated teeth among dental practitioners in Saudi Arabia. A nationwide pilot survey. Dentistry Journal, 6(3), 44.

16. Johnson, M. E., Stewart, G. P., Nielsen, C. J., \& Hatton, J. F. (2000). Evaluation of root reinforcement of endodontically treated teeth. Oral Surgery, Oral Medicine, Oral Pathology, Oral Radiology, and Endodontology, 90(3), 360-364.

17. Pereira, J. R., De Ornelas, F., Conti, P. C. R., \& Do Valle, A. L. (2006). Effect of a crown ferrule on the fracture resistance of endodontically treated teeth restored with prefabricated posts. The Journal of prosthetic dentistry, 95(1), 50-54.

18. Habib, S. R., Al Rifaiy, M. Q., Alkunain, J., Alhasan, M., \& Albahrani, J. (2014). Concepts of restoring endodontically treated teeth among dentists in Saudi Arabia. The Saudi Journal for Dental Research, 5(1), 15-20.

19. Ferrari, M., Mason, P. N., Goracci, C., Pashley, D. H., \& Tay, F. R. (2004). Collagen degradation in endodontically treated teeth after clinical function. Journal of dental research, 83(5), 414-419.

20. Kinney, J. H., Nalla, R. K., Pople, J. A., Breunig, T. M., \& Ritchie, R. O. (2005). Age-related transparent root dentin: mineral concentration, crystallite size, and mechanical properties. Biomaterials, 26(16), 3363-3376.

21. Bayram, H. M., Çelikten, B., Bayram, E., \& Bozkurt, A. (2013). Fluid flow evaluation of coronal microleakage intraorifice barrier materials in endodontically treated teeth. European journal of dentistry, 7(3), 359-362. 